\title{
Liposomal Oxaliplatin
}

National Cancer Institute

\section{Source}

National Cancer Institute. Liposomal Oxaliplatin. NCI Thesaurus. Code C65110.

The liposomal preparation of oxaliplatin, an organoplatinum complex in which the platinum atom is complexed with 1,2-diaminocyclohexane (DACH) and with an oxalate ligand as a 'leaving group'. A leaving group is an atom or a group of atoms that is displaced as a stable species taking with it its bonding electrons. After displacement of the labile oxalate ligand leaving group, the active oxaliplatin derivatives (monoaquo and diaquo DACH platinum) alkylate macromolecules, and form both inter- and intra-strand platinum-DNA crosslinks, thereby inhibiting DNA replication and resulting in cytotoxicity. The DACH side chain appears to inhibit DNA repair mechanism, therefore overcoming the limits observed in other platinum-based therapies. 